\title{
Protection of photoreceptors by intravitreal injection of the Y-27632 Rho-associated protein kinase inhibitor in Royal College of Surgeons rats
}

\author{
TING ZHANG $^{1}$, YANTAO WEI ${ }^{1}$, XINTONG JIANG $^{1}$, JINGMING LI $^{2}$, SUO QIU $^{1}$ and SHAOCHONG ZHANG ${ }^{1}$ \\ ${ }^{1}$ State Key Laboratory of Ophthalmology, Zhongshan Ophthalmic Center, Sun Yat-Sen University, Guangzhou, \\ Guangdong 510060; ${ }^{2}$ Department of Ophthalmology, Affiliated Eye Hospital of Nanchang University, \\ Nanchang, Jiangxi 330000, P.R. China
}

Received July 19, 2014; Accepted April 10, 2015

DOI: $10.3892 / \mathrm{mmr} .2015 .3889$

\begin{abstract}
Retinitis pigmentosa (RP) is an inherited retinal disease, which is characteristic by degeneration of the rod and cone photoreceptors. The present study aimed to assess the protective effects on photoreceptors of intravitreal injection of Y-27632, a specific inhibitor of Rho-associated protein kinase (ROCK), in a Royal College of Surgeons (RCS) rat model. Different concentrations of Y-27632 (1-50 mM) were administered by intravitreal injection into the RCS rats. The effects of Y-27632 were recorded using electroretinography (ERG), measuring the thicknesses of the retinal outer nuclear layer (ONL) and examination of apoptotic markers using terminal deoxynucleotidyl transferase dUTP nick end labeling (TUNEL) staining and western blot analysis. Treatment of the eyes with Y27632 at 10 or $50 \mathrm{mM}$, led to a $30 \%$ increase in a- and b-wave amplitudes in ERG, and an increase in ONL thickness by $10 \%$, compared with the $1 \mathrm{mM}$ Y-27632-treated and vehicle (phosphate-buffered saline; PBS)-treated groups. In addition, eyes treated with $10 \mathrm{mM}$ Y27632 exhibited a 90\% decrease in TUNEL-positive cells, accompanied by decreased protein expression levels of active caspase 3 and Bax by $50 \%$, and a $90 \%$ increase in the ratio of $\mathrm{Bcl}-2 / \mathrm{Bax}$, compared with the PBS-treated groups. These data suggested that Y-27632 protected retinal function by inhibiting the apoptosis of photoreceptor cells in the RCS rat model. The present study demonstrated for the first time, to the best of our knowledge, to report the use of Y-27632 for protection against
\end{abstract}

Correspondence to: Professor Shaochong Zhang, State Key Laboratory of Ophthalmology, Zhongshan Ophthalmic Center, Sun Yat-Sen University, 54 South Xianlie Road, Guangzhou, Guangdong 510060, P.R. China

E-mail: zhshaochong@163.com

Key words: apoptosis, photoreceptor cell, Royal College of Surgeons rat, retinal degeneration, Rho-associated protein kinase inhibitor
RP in an RCS rat model. Y-27632 may be a potential candidate for the treatment of human RP.

\section{Introduction}

Retinitis pigmentosa (RP) describes a group of inherited retinal diseases, characterized by the progressive loss of photoreceptors, resulting in night blindness and visual field constriction (1). The worldwide prevalence of RP is $\sim 1 / 4,000$, which affects $>1$ million individuals. The family of disease that are phenotypically recognized as RP consists of $>150$ genotypically distinct entities (2). Despite the different genotypes, the loss of vision in RP is associated with the death of photoreceptor cells. Previous studies have indicated that apoptosis is the dominant mechanism of photoreceptor death in Royal College of Surgeons (RCS) rats, which are one of the animal models of RP $(3,4)$. Portera-Cailliau et al (5) suggested that retinal degeneration may be slowed by interfering with apoptotic mechanisms. Therefore, therapeutic strategies, which target a common mechanism of photoreceptor death among a multitude of genotypes may offer a broad clinical application for the treatment of RP.

It has been well-documented that the small GTP-binding protein, Rho, contributes to the regulation of neurite outgrowth (6-8) and apoptosis (9) in neuronal cells. In addition, Rho-associated protein kinase (ROCK), one of the key effectors of Rho, is involved in growth factor signaling $(10,11)$, the regulation of apoptosis (12) and cell survival (13). These proteins are abundantly expressed in various types of cell (14), including those in the retina (15-17). Previous reports have demonstrated that the activation of RhoA, one of the Rho family GTPases, can induce retinal degeneration (18). The intravitreal administration of HA-1077 or Y-27632, which are specific ROCK inhibitors, has been observed to improve retinal function in a mouse model of Huntington's Disease with progressive retinopathy (19), and to rescue retinal ganglion cells in rat models of diabetes and transient retinal ischemia (18). The present study hypothesized that the photoreceptor degeneration in RP may be treated by intravitreal administration of Y-27632, via the inhibition of apoptosis in RCS rats. This is the first time, to the best of our knowledge, that Y-27632 that has been used for RP in RCS rat models. 


\section{Materials and methods}

Animal model. A total of 20 male and 20 female dystrophic RCS rats (rdy+p+; 21 days-old), obtained from the Third Military Medical University (Xian, China) were used in the present study. The rats were housed in cages (one rat/cage), maintained in standard conditions (room temperature $23 \pm 2 \mathrm{C}$; relative humidity $60 \pm 10 \% ; 12 \mathrm{~h}$ light/dark cycle), and were fed a standard laboratory diet with ad libitum access to water. Prior to all experiments, the ocular surface integrity was examined by slit-lamp microscope (OMS-85; Topcon, Tokyo, Japan). At the point of intravitreal injection, development of the rods and cones in the rats had been completed (20) and electroretinograph (ERG) responses were normal amplitudes (21). The rats were anesthetized and sacrificed by intraperitoneal injection of $10 \%$ chloral hydrate (China Otsuka Pharmaceutical Co., Ltd., Tianjin, China), following which the eyes were immediately enucleated. The animals were maintained and treated in accordance with the ARVO Statement for the Use of Animals in Ophthalmic and Vision Research and the present study was approved by the animal ethics committee of Zhongshan Ophthalmic Center, Sun Yat-sen University (Guanzhou, China; approval no. ID:2012-12).

Experimental design. A total of 40 RCS rats were used for ERG recording and measurements of the ONL thickness. The rats were divided into four groups ( $\mathrm{n}=10$ in each group): $1 \mathrm{mM}$ Y27632 intravitreal injection, $10 \mathrm{mM}$ Y27632; $50 \mathrm{mM}$ Y27632 and phosphate-buffered saline (PBS) control groups. A total of 20 RCS rats were used for terminal deoxynucleotidyl transferase-mediated biotinylated-dUTP nick-end labeling (TUNEL) assays and to determine the expression levels of active caspase 3, Bax and $\mathrm{Bcl}-2$. These rats were divided into two groups (n=10 in each group): A 10 mM Y27632 and a PBS $(1 \mu \mathrm{l})$ control group.

Y-27362 administration. The dosage effects of Y-27632 (Wako Pure Chemicals Industries, Ltd., Osaka, Japan) on the morphology and function of the retina were assessed by injecting 1,10 or $50 \mathrm{mM} \mathrm{Y-27632} \mathrm{into} \mathrm{the} \mathrm{vitreous}(0.1,1$ and $5 \mathrm{mM}$ final concentrations, respectively, on day $21(\mathrm{n}=10)$. The doses were selected based on the successful neuroprotection of retinal ganglion cells, demonstrated using a dose of $100 \mathrm{nmol} / \mathrm{eye}$, which was equal to the final concentration of $1 \mathrm{mM}$ used in the present study $(18,22)$. The inhibitory effects of Y-27632 on the apoptosis of the photoreceptor were analyzed by injecting $10 \mathrm{mMY}-27632$ on day $21(\mathrm{n}=10)(20)$. Each concentration of Y-27632 was diluted in PBS to the same final volume $(1 \mu \mathrm{l})$ for the intravitreal injection. The control group was intravitreally injected with $1 \mu \mathrm{l}$ PBS, instead of Y-27632 (n=10).

Intravitreal injections were performed under an operating microscope (OPMI VISU 200; Carl Zeiss AG, Oberchoken, Germany), using a microsyringe (Hamilton, Reno, NV, USA) with a 30-gauge needle (Hamilton). The needle was inserted $\sim 1 \mathrm{~mm}$ behind the corneal limbus.

$E R G$ recording. The ERG recording was performed on day 28 , according to Mandal et al (23). ERGs were monitored using a Neuropack $\alpha$ electophysiological recorder (Nihon Kohden
Corp., Tokyo, Japan). Briefly, following $12 \mathrm{~h}$ dark adaptation under dim red light, the animals were anesthetized by intramuscular administration of a mixture of $100 \mathrm{mg} / \mathrm{kg}$ ketamine and $10 \mathrm{mg} / \mathrm{kg}$ xylazine (Shenyang Sinqi Pharmaceutical Co., Ltd., Shenyang, China). The pupils were dilated with $0.5 \%$ tropicamide (Shenyang Sinqi Pharmaceutical Co., Ltd.) and body temperature was maintained at $\sim 37^{\circ} \mathrm{C}$ with a heating pad (Beijing Gaoshiyuanwang Technologies Co., Ltd., Beijing, China). ERGs were recorded from each eye using a gold loop electrode (Beijing Gaoshiyuanwang Technologies Co., Ltd.) on the corneal surface, maintained with Lacrigel lubricating ointment (Laboratoires Europhta, Monaco). A reference electrode was attached to the shaven skin on the head and a ground electrode was clipped to the animal skin of the tail. The amplitudes of a-wave and b-wave were measured from the average of three responses by a set of three flashes of stimulation, using two flash intensities, 1,000 and $2,000 \mathrm{~cd} \cdot \mathrm{s} / \mathrm{m}^{2}$.

Measurement of the ONL thickness. Following the ERG recording, the animals were sacrificed by carbon dioxide asphyxiation. The animal's eyes were removed, fixed with $4 \%$ paraformaldehyde and embedded in paraffin. Sections ( $5 \mu \mathrm{m}$ thick) of eyeballs were cut along the vertical meridian through the optic nerve head. The sections were dewaxed with xylene, rehydrated with anhydrous ethanol and stained with hematoxylin and eosin (Sigma-Aldrich, St. Louis, MO, USA). The ONL thickness was measured under a light microscope (Axioplan2; Carl Zeiss Meditec, Inc., Jena, Germany). Measurements were made at $300 \mu \mathrm{m}$ intervals in nine defined areas, starting at the optic nerve, and extending toward the superior and inferior ora serrata, according to LaVail et al (24). The ONL thickness measurements were averaged within each group to provide a single value for statistical analysis.

TUNEL assay. A TUNEL assay was performed to detect apoptosis on the cryosections of the rat eyes using the in situ Cell Death Detection TMR Red kit (Roche Diagnostics, Indianapolis, IN, USA). For staining of the sections, the samples were permeabilized for $2 \mathrm{~min}$ in cold PBS, containing $0.1 \%$ Triton X-100 and were subsequently incubated at $37^{\circ} \mathrm{C}$ in the TUNEL reaction mix, which contained nucleotides and terminal deoxynucleotidyl transferase (TdT). Incubation in the absence of the TdT enzyme was performed as a negative vehicle control. The sections were subsequently mounted (VECTASHIELD mounting medium with DAPI; Vector Laboratories, Inc., Burlingame, CA, USA), and visualized by confocal microscopy (LSM510; Carl Zeiss AG). The apoptotic index of the ONL was calculated as the number of TUNEL-positive nuclei / number of photoreceptor cell nuclei, as previously described by Kyger et al (25).

Western blot analysis. The rat retinas were dissected using a surgical microscope and lysed in buffer, containing $1 \mathrm{M}$ Tris- $\mathrm{HCl}$ $(\mathrm{pH} 7.5), 1 \%$ Triton $\mathrm{X}-100,1 \%$ nonidet $\mathrm{P}-40,10 \%$ sodium dodecyl sulfate, $0.5 \%$ sodium deoxycholate, $0.5 \mathrm{M}$ EDTA, $10 \mu \mathrm{g} / \mathrm{ml}$ leupeptin, $10 \mu \mathrm{g} / \mathrm{ml}$ aprotinin, and $1 \mathrm{mM}$ phenylmethylsulfonyl fluoride. The retinal protein concentrations were determined using a bicinchoninic acid assay (Pierce Biotechnology, Inc., Rockford, IL, USA). The retinal proteins $(25 \mu \mathrm{g})$ were separated using SDS-PAGE and transferred onto a 
polyvinylidine difluoride filter membrane (Millipore, Bedford, MA, USA). The membranes were then blocked with skimmed milk at room temperature for $2 \mathrm{~h}$. Subsequently, the membrane was incubated with primary polyclonal antibodies against active caspase 3 (anti-mouse; 1:1,000; Santa Cruz Biotechnology, Inc., Dallas, TX, USA), Bcl-2 (anti-mouse; 1:1,000; Sigma-Aldrich), Bax (anti-rabbit; 1:1,000; Cell Signaling Technology, Inc., Danvers, MA, USA) or $\beta$-actin (anti-mouse, 1:1,000; Santa Cruz Biotechnology, Inc.) at $4^{\circ} \mathrm{C}$ overnight. The membrane was subsequently incubated with goat-anti-rabbit or goat-anti-mouse conjugated horseradish peroxidase secondary antibody (1:2,000; Southern-Biotech, Birmingham, AL, USA) for $2 \mathrm{~h}$ at room temperature. The membranes were visualized using an enhanced chemiluminescence system (Pierce Biotechnology, Inc.).

Statistical analyses. One-way analysis of variance, followed by Bonferroni's multiple-comparison test was used for statistical analyses. The data are expressed as the mean \pm standard error of the mean. Statistical analyses were conducted using SPSS version 16.0 (SPSS Inc., Chicago, IL, USA). P<0.05 was considered to indicate a statistically significant difference.

\section{Results}

Protective effect of $Y-27632$ on the retinal function of $R C S$ rats. To investigate the effect on the retinal function of intravitreal injection of Y-27632, the present study analyzed the scotopic mixed rod-cone ERG a- and b-wave amplitudes 1 week following injection. Treatment with 10 or $50 \mathrm{mM} \mathrm{Y-27632}$ significantly increased the a- and b-wave amplitudes by $\sim 30 \%$, compared with the $1 \mathrm{mM}$ Y-27632-treated and control groups $(\mathrm{P}<0.01)$. However, no significant changes were observed between the $1 \mathrm{mM}$ Y-27632-treated and control groups ( $\mathrm{P}>0.05$ ), or between the $10 \mathrm{mM}$ and $50 \mathrm{mM}$ Y-27632-treated groups ( $\mathrm{P}>0.05$; Fig. 1A-C).

Protective effect of Y-27632 on the ONL thickness of RCS rats. The present study then investigated whether retinal morphology was altered following Y-27632 injection by analyzing the ONL thickness. No significant differences were observed in the ONL thickness between the control and $1 \mathrm{mM}$ Y-27632-treated eyes, however, the ONL thicknesses in the 10 and $50 \mathrm{mM}$ Y-27632-treated eyes were significantly higher than those in the control and $1 \mathrm{mM}$ Y-27632-treated eyes 1 week post-injection. No significant differences were observed between the ONL thicknesses of the eyes in the 10 and $50 \mathrm{mM}$ Y-27632 groups (Fig. 2A and B). According to these findings, the dosage of $10 \mathrm{mM}$ Y-27632 was used as the minimum and effective concentration in the subsequent experiments.

Protective effect of Y-27632 on photoreceptor apoptosis in RCS rats. To determine whether Y-27632 affected the apoptosis of photoreceptors in RCS rats, in situ labeling using a TUNEL assay was performed in the retinal tissues of the rats. An abundance of TUNEL-positive cells (red) were detected in the retina of the control group 1 week post-injection. However, the number of TUNEL-positive cells in the $10 \mathrm{mM}$ Y-27632-treated eyes was markedly lower. In each group, the TUNEL-positive
A
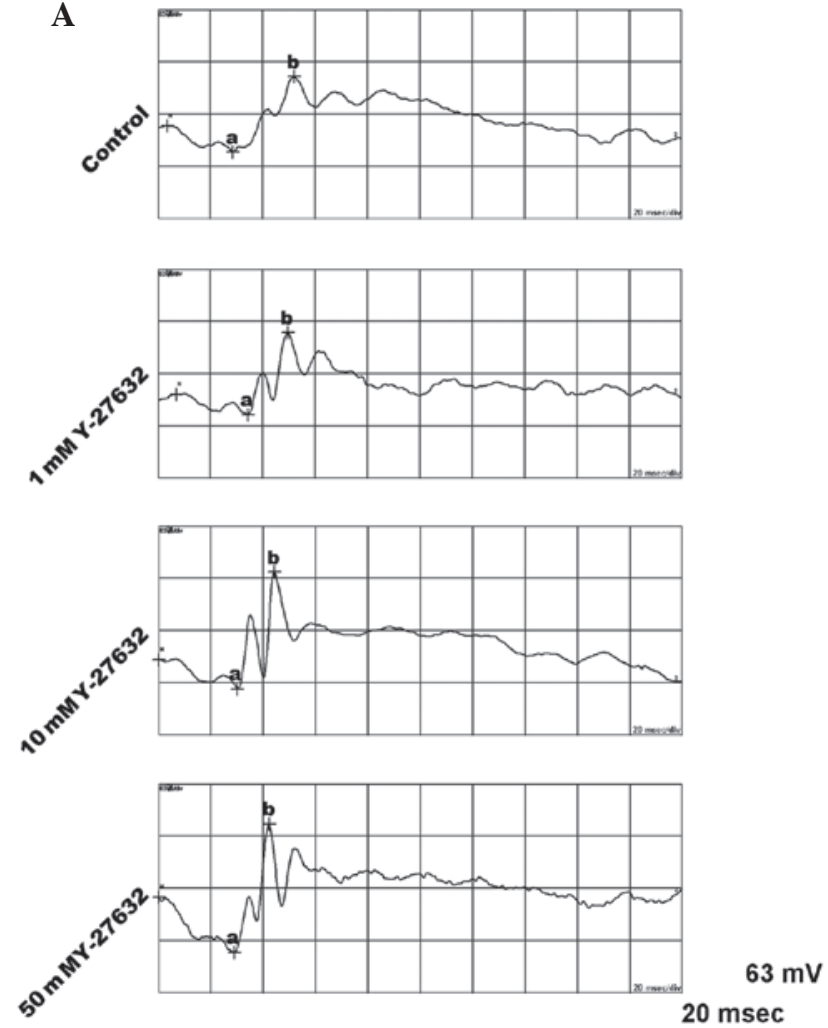

B

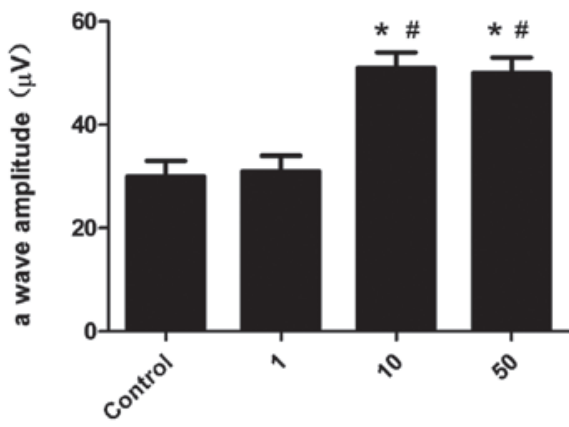

Y-27632 concentrations (mM)

C

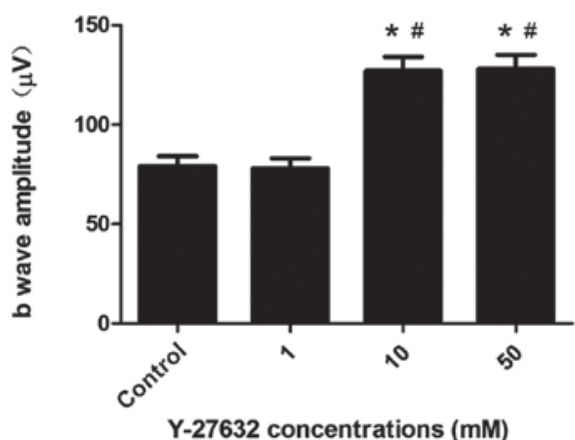

Figure 1. Treatment with Y-27632 (10 or $50 \mathrm{mM}$ ) inhibits the decrease of aand b-wave amplitude in RCS rats. (A) ERG recording, (B) a-wave amplitude and $(\mathrm{C}) \mathrm{b}$-wave amplitude 1 week post-injection. No significant changes in the a- and b-wave amplitude were observed in the Y-27632-treated (1 mM) eyes compared with the controls $(\mathrm{P}>0.05 ; \mathrm{n}=10)$. Y-27632-treated (10 or $50 \mathrm{mM}$ ) eyes exhibited $30 \%$ higher a- and b-wave amplitudes compared with the $1 \mathrm{mM}$ Y-27632-treated eyes and the controls $\left(\mathrm{n}=10 ;{ }^{*} \mathrm{P}<0.01\right.$, compared with the $1 \mathrm{mM}$ Y-27362-treated eyes and ${ }^{\text {}} \mathrm{P}<0.01$, compared with the controls). However, no significant changes were observed between the eyes treated with 10 and 50 mM Y-27362 (P>0.05; n=10). RCS, Royal College of Surgeons; ERG, electroretinography. 
A

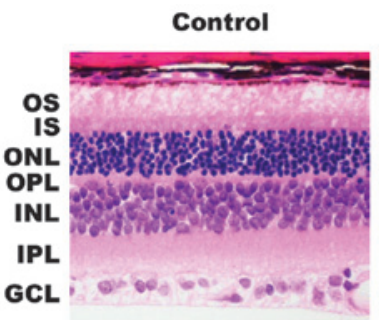

$1 \mathrm{mM}$ Y-27632

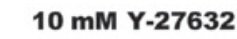

$50 \mathrm{mM}$ Y-27632
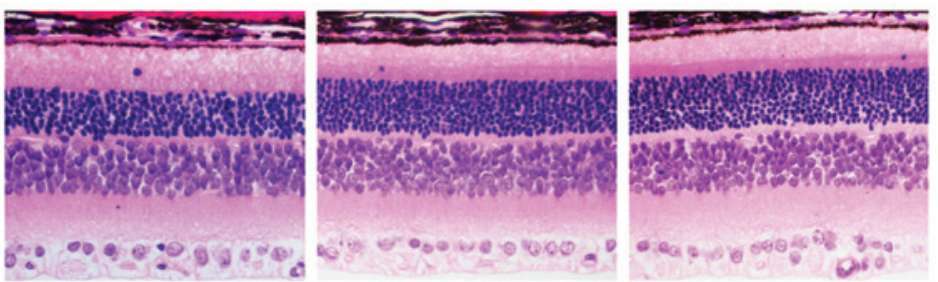

B

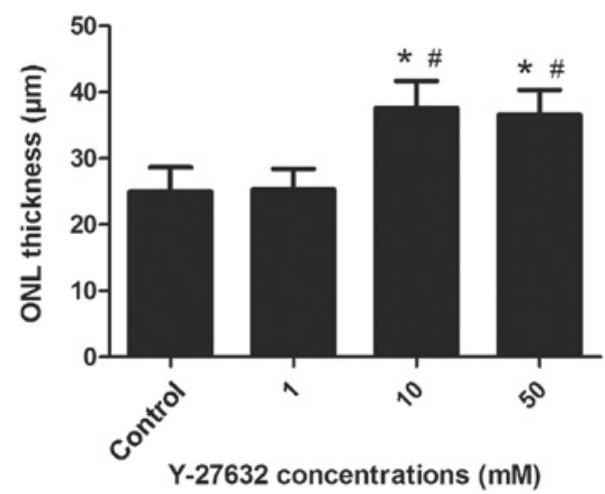

Figure 2. Treatment with Y-27632 (10 or $50 \mathrm{mM}$ ) alteres retinal morphology in RCS rats. (A) Representative retinal sections are shown. (B) Quantification of the ONL thickness 1 week post-injection. Y-27632-treated $(1 \mathrm{mM})$ eyes demonstrated no significant changes in ONL thickness compared with the controls $(\mathrm{n}=10 ; \mathrm{P}>0.05)$. Y-27632-treated $(10$ or $50 \mathrm{mM})$ eyes exhibited $25 \%$ thicker ONLs compared with the $1 \mathrm{mM} \mathrm{Y-27632-treated} \mathrm{eyes}(" \mathrm{P}<0.01 ; \mathrm{n}=10)$ and controls $\left.\left({ }^{*} \mathrm{P}<0.01\right) . \mathrm{n}=10\right)$. However, no significant changes was observed between the eyes treated with $10 \mathrm{mM}$ and $50 \mathrm{mM} Y-27362(\mathrm{P}>0.05 ; \mathrm{n}=10)$. Scale bar=40 $\left.\mu \mathrm{m}\right)$. RCS, Royal College of Surgeons; OS, outer surface, IS, inner surface; ONL, outer nuclear layer, INL, inner nuclear layer; IPL, inner plexiform layer; GCL, ganglion cell layer.

A
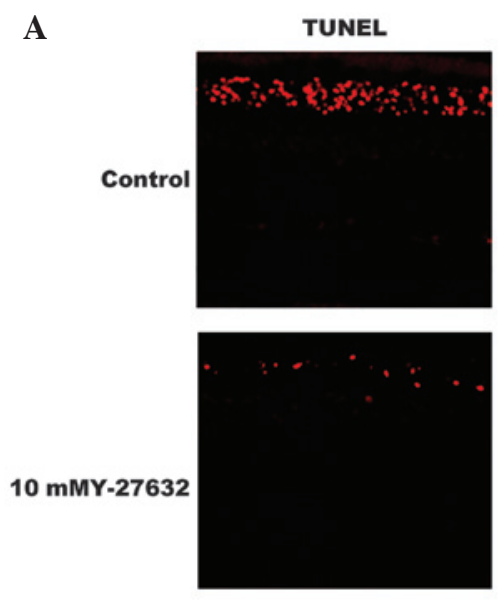
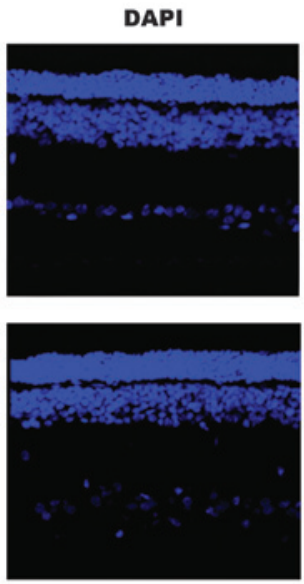

B

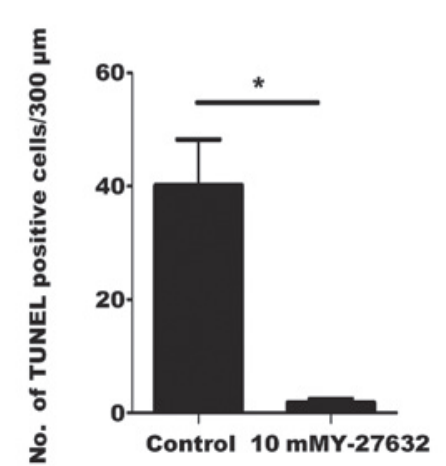

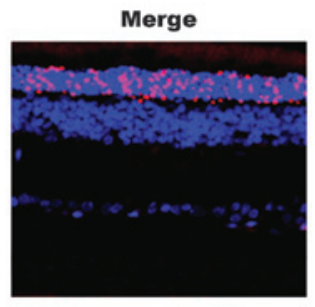

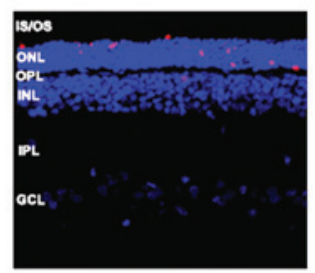

Figure 3. Analysis was performed using a TUNEL assay and visualization under confocal microscopy. The Y-27632 inhibited the apoptosis of photoreceptors induced in the RCS rats. (A) Abundant levels of TUNEL-positive cells (red) were observed in the ONL of the control retinas 1 week post-injection, however, a marked reduction in TUNEL-positive cells (red) was detected in the $10 \mathrm{mM} \mathrm{Y-27632-treated} \mathrm{retinas.} \mathrm{Representative} \mathrm{microscopy} \mathrm{images} \mathrm{are} \mathrm{shown} \mathrm{(scale}$ bar $=40 \mu \mathrm{m}$ ). (B) Administration of Y-27632 significantly decreased the levels of apoptosis 1 week post-injection compared with the control ("P<0.01; $\mathrm{n}=10$ ). The nuclei were counterstained with DAPI (blue). RCS, Royal College of Surgeons; ONL, outer nuclear layers; TUNEL, terminal deoxynucleotidyl transferase dUTP nick end labeling; DAPI, 4',6-diamidino-2-phenylindole;OS, outer surface, IS, inner surface; ONL, outer nuclear layer, INL, inner nuclear layer; IPL, inner plexiform layer; GCL, ganglion cell layer. 
A

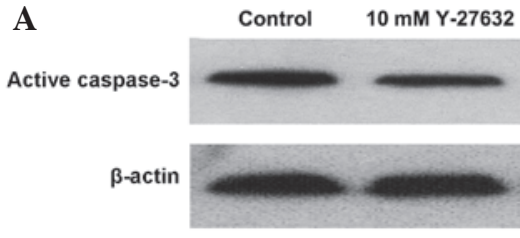

C

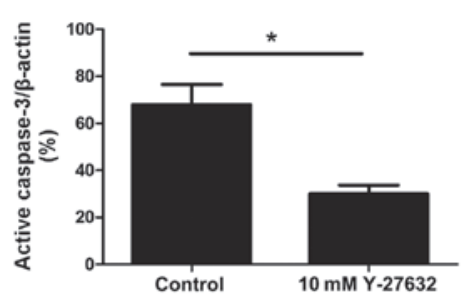

E

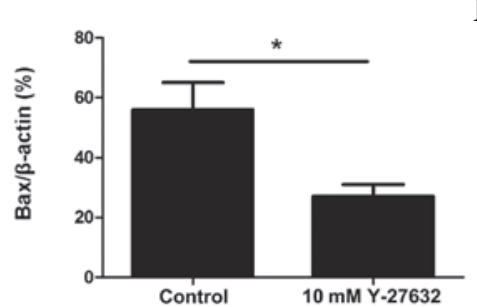

B

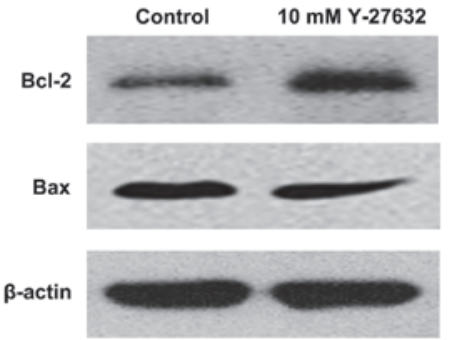

D

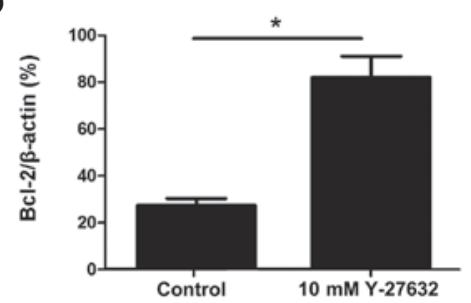

F

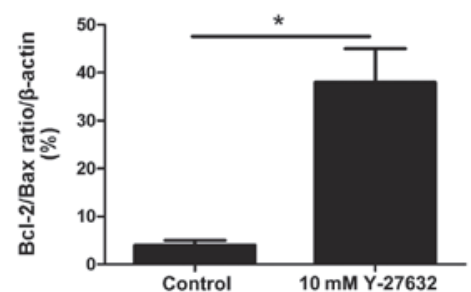

Figure 4. Effects of treatment with Y-27632 on the expression levels of active caspase 3, Bcl-2 and Bax in the retina. The protein expression levels of active (A) caspase 3, (B) Bcl-2 and Bax in the retina were determined using western blot analysis. (C) Protein expression levels of active caspase 3 were significantly lower in the $10 \mathrm{mM} \mathrm{Y-27632-treated} \mathrm{rats} \mathrm{compared} \mathrm{with} \mathrm{the} \mathrm{normal} \mathrm{saline} \mathrm{(NS)-treated} \mathrm{rats}{ }^{*} \mathrm{P}<0.01 ; \mathrm{n}=10$ ). The protein expression levels of (D) Bcl-2 and (E) Bax in the retinas were determined using western blot analysis and the (F) Bcl-2/Bax ratio was calculated. Treatment with $10 \mathrm{mM} \mathrm{Y-27632} \mathrm{caused} \mathrm{a}$ significant increase in the Bcl-2/Bax ratio compared with the NS-treated rats at day 28 ("P<0.01; $\mathrm{n}=10)$.

cells were present only in the ONL. The administration of $10 \mathrm{mM}$ Y-27632 significantly decreased the apoptosis of photoreceptors compared with the PBS-injected control group $(\mathrm{P}<0.01)$, as shown in Fig. $3 \mathrm{~A}$ and $\mathrm{B})$.

Y-27632 increases the protein expression of Bcl-2 and decreases the protein expression levels of caspase 3 and Bax in RCS rats. The present study investigated the effect of Y-27632 on the expression levels of caspase 3, Bax and Bcl-2 in the RCS rat retina via western blot analysis. The protein expression levels of active caspase 3 and Bax in the $10 \mathrm{mM}$ Y-27632-treated retinas markedly decreased 1 week post-injection. However, administration of $10 \mathrm{mM}$ Y-27632 markedly increased the protein expression of $\mathrm{Bcl}-2$. Furthermore the $\mathrm{Bcl}-2 / \mathrm{Bax}$ ratio in the $10 \mathrm{mM}$ Y-27632-treated retinas was 10-fold higher than that in the PBS-treated retinas (Fig. 4A and B). The difference in levels of active caspase 3, $\mathrm{Bax}$ and $\mathrm{Bcl}-2$, and the $\mathrm{Bcl}-2 / \mathrm{Bax}$ ratio were statistically significant between the $10 \mathrm{mM}$ Y-27632-treated and PBS-treated groups $(\mathrm{P}<0.01$; Fig. 4C-F $)$.

\section{Discussion}

Previous studies have demonstrated that RhoA is sufficient to induce the neuronal excitotoxic pathway, which indicates that Rho is an essential component of the excitotoxic neuronal cell death pathway (26). It is understood that treatment with Y-27632 inhibits neurodegeneration in models of huntingtin degradation (27,28), Parkinson's disease (29) and Alzheimer's disease (30). In addition, a previous study demonstrated that HA-1077, or Fasudil, which is another selective inhibitor of ROCK, is an efficacious therapeutic molecule that slows the progression of photoreceptor degeneration (19). Furthermore, it has been reported that Y26732-supplemented culture media reduces dissociation-induced apoptosis in vivo and in vitro. Koyanagi et al (31) revealed that Y26732 rescues transplanted neural precursor cells from apoptosis in a mouse transplantation model. Claassen et al (32) also demonstrated that supplementation of cell culture media with $10 \mu \mathrm{M}$ Y-26732 efficiently reduced apoptosis and increased the survival and proliferation of dissociated human embryonic stem cell-derived neural progenitor cells in vitro. Collectively, these findings suggested that Y-26732 can be used for the treatment of degeneration of photoreceptors in RP.

The present study demonstrated that intravitreal injection of the Y-27632 ROCK inhibitor prevented photoreceptor degeneration in RCS rats. Human RP can be diagnosed by changes in ERG. In the scotopic flash ERG, the a-wave primarily represents the mixed function of cones and rods, and the $b$-wave predominantly reflects light-induced depolarization of ONL bipolar cells, but may be altered by the activity of other cells, including the responses of Müller cells (33). The present study demonstrated significant preservation of a- and b-wave amplitudes in the ERG assays in the retinal tissues of rats treated with 10 and $50 \mathrm{mM}$ Y-27632 1 week post-injection. In addition, the numbers of cells in the ONL in the 10 and $50 \mathrm{mM}$ Y-27632-treated groups were significantly 
higher, compared with those in the $1 \mathrm{mM}$-treated and the vehicle-injected eyes. The present study also demonstrated that no preservation of photoreceptors occurred in the $1 \mathrm{mM}$ Y-27632-treated group, whereas 10 and $50 \mathrm{mM}$ Y-27632 did preserve the photoreceptors. These findings indicated that, for the preservation of photoreceptors in RCS rats, 10 or $50 \mathrm{mM}$ Y-27632 provided an effective dose. Therefore, a minimum and effective concentration of $10 \mathrm{mM} \mathrm{Y-27632,} \mathrm{was}$ used in the subsequent experiments.

These findings were supported by the effect on the apoptosis of photoreceptors. Apoptosis is the predominant mechanism of photoreceptor degeneration in RCS rats (4). As described previously in RCS rats (34), the photoreceptor outer segments are irregularly aligned, with vacuolation in the inner segments and TUNEL-positive cells in 50\% of the outer retinal layers on day 30 (4). The observations in the present study using PBS-injected RCS rats were consistent with these findings. By contrast, when $10 \mathrm{mM}$ Y-27632 was administered intravitreally, the number of TUNEL-positive cells (red) in the outer retina was significantly reduced.

A number of studies have suggested that activation of the caspase family is important in the execution of apoptotic events $(35,36)$. The activation of caspase-like proteases is important in the apoptosis of photoreceptors in RCS rats (37). In the present study, western blot analysis revealed that the expression of active caspase 3 in the retina of the RCS rats was decreased following treatment with $10 \mathrm{mM} \mathrm{Y-27632.} \mathrm{The}$ Bcl-2 family of proteins, consisting of pro-apoptotic Bax and anti-apoptotic Bcl-2 members, is important in the regulation of neuronal apoptosis. Apoptosis can be inhibited by the inhibition of the expression of the apoptosis-associated genes, including Bax, or by the overexpression of $\mathrm{Bcl}-2(38,39)$. Previous studies have demonstrated that Bax is upregulated in photoreceptors and Bcl-2 was not downregulated in RCS rat retinas on day 28 compared with day 21 (40). The role of the Bcl-2 family in the apoptotic process of photoreceptors remains to be elucidated (41). The present study demonstrated that the protein expression of $\mathrm{Bcl}-2$ and the ratio of $\mathrm{Bcl}-2 / \mathrm{Bax}$ were increased, while the protein expression of Bax was reduced in the $10 \mathrm{mM}$ Y-27632-treated retinas compared with the PBS-treated retinas on day 28. Taken together, these findings indicated that Y-27632 may inhibit the apoptosis of photoreceptors via a caspase-dependent pathway in the RCS rat, and the Bcl-2 family may be involved in this process.

In conclusion, the present study demonstrated that a single intravitreal injection of Y-27632 had a significant protective effect on photoreceptor degeneration, morphologically and functionally, by inhibiting the apoptosis of photoreceptors in the RCS rat retinas. Therefore, the intravitreal administration of Y-27632 is a potential candidate as a novel therapeutic strategy for photoreceptor degeneration, including RP. However, further investigation of the underlying mechanisms of Y-27632 on photoreceptor protection is required to improve the efficiency of protection for clinical therapeutic use.

\section{Acknowledgements}

This study was supported by grants from the National Natural Science Foundation of China (no. 81170866) and the Guangdong Science and Technology Plan Project (no. 2012B031800380).

\section{References}

1. Dryja TP and Li T: Molecular genetics of retinitis pigmentosa. Hum Mol Genet 4 Spec No: 1739-1743, 1995.

2. van Soest S, Westerveld A, de Jong PT, Bleeker-Wagemakers EM and Bergen AA: Retinitis pigmentosa: defined from a molecular point of view. Surv Ophthalmol 43: 321-334, 1999.

3. Travis GH: Mechanisms of cell death in the inherited retinal degenerations. Am J Hum Genet 62: 503-508, 1998.

4. Tso MO, Zhang C, Abler AS, et al: Apoptosis leads to photoreceptor degeneration in inherited retinal dystrophy of RCS rats. Invest Ophthalmol Vis Sci 35: 2693-2699, 1994.

5. Portera-Cailliau C, Sung CH, Nathans J and Adler R: Apoptotic photoreceptor cell death in mouse models of retinitis pigmentosa. Proc Natl Acad Sci USA 91: 974-978, 1994.

6. Arakawa Y, Bito H, Furuyashiki T, et al: Control of axon elongation via an SDF-1alpha/Rho/mDia pathway in cultured cerebellar granule neurons. J Cell Biol 161: 381-391, 2003.

7. van Galen EJ and Ramakers GJ: Rho proteins, mental retardation and the neurobiological basis of intelligence. Prog Brain Res 147: 295-317, 2005

8. Woo S and Gomez TM: Rac1 and RhoA promote neurite outgrowth through formation and stabilization of growth cone point contacts. J Neurosci 26: 1418-1428, 2006.

9. Dubreuil CI, Winton MJ and McKerracher L: Rho activation patterns after spinal cord injury and the role of activated Rho in apoptosis in the central nervous system. J Cell Biol 162: 233-243, 2003.

10. Burridge $\mathrm{K}$ and Wennerberg $\mathrm{K}$ : Rho and Rac take center stage. Cell 116: 167-179, 2004

11. Ali TK, Al-Gayyar MM, Matragoon S, et al: Diabetes-induced peroxynitrite impairs the balance of pro-nerve growth factor and nerve growth factor and causes neurovascular injury. Diabetologia 54: 657-668, 2011.

12. Linseman DA and Loucks FA: Diverse roles of Rho family GTPases in neuronal development, survival and death. Front Biosci 13: 657-676, 2008.

13. Aznar S and Lacal JC: Rho signals to cell growth and apoptosis. Cancer Lett 165: 1-10, 2001.

14. Ridley AJ: Rho family proteins: coordinating cell responses. Trends Cell Biol 11: 471-477, 2001.

15. Yonemura S, Hirao-Minakuchi K and Nishimura Y: Rho localization in cells and tissues. Exp Cell Res 295: 300-314, 2004.

16. Kitaoka Y, Kitaoka Y, Kumai T, et al: Involvement of RhoA and possible neuroprotective effect of fasudil, a Rho kinase inhibitor, in NMDA-induced neurotoxicity in the rat retina. Brain Res 1018: 111-118, 2004.

17. Mitchell DC, Bryan BA, Liu JP, et al: Developmental expression of three small GTPases in the mouse eye. Mol Vis 13: 1144-1153, 2007.

18. Al-Gayyar MM, Mysona BA, Matragoon S, et al: Diabetes and overexpression of proNGF cause retinal neurodegeneration via activation of RhoA pathway. PLoS One 8: e54692, 2013.

19. Li M, Yasumura D, Ma AA, et al: Intravitreal administration of HA-1077, a ROCK inhibitor, improves retinal function in a mouse model of huntington disease. PLoS One 8: e56026, 2013.

20. Huang YM, Yin ZQ, Liu K and Huo SJ: Temporal and spatial characteristics of cone degeneration in RCS rats. Jpn J Ophthalmol 55: 155-162, 2011.

21. Sauvé Y, Lu B and Lund RD: The relationship between full field electroretinogram and perimetry-like visual thresholds in RCS rats during photoreceptor degeneration and rescue by cell transplants. Vision Res 44: 9-18, 2004.

22. Hirata A, Inatani M, Inomata Y, et al: Y-27632, a Rho-associated protein kinase inhibitor, attenuates neuronal cell death after transient retinal ischemia. Graefes Arch Clin Exp Ophthalmol 246: 51-59, 2008.

23. Mandal MN, Patlolla JM, Zheng L, et al: Curcumin protects retinal cells from light-and oxidant stress-induced cell death. Free Radic Biol Med 46: 672-679, 2009.

24. LaVail MM, Sidman RL and Gerhardt CO: Congenic strains of RCS rats with inherited retinal dystrophy. J Hered 66: 242-244, 1975.

25. Kyger M, Worley A and Adamus G: Autoimmune responses against photoreceptor antigens during retinal degeneration and their role in macrophage recruitment into retinas of RCS rats. J Neuroimmunol 254: 91-100, 2013.

26. Satoh S, Utsunomiya T, Tsurui K, et al: Pharmacological profile of hydroxy fasudil as a selective rho kinase inhibitor on ischemic brain damage. Life Sci 69: 1441-1453, 2001. 
27. Bauer PO and Nukina N: Enhanced degradation of mutant huntingtin by rho kinase inhibition is mediated through activation of proteasome and macroautophagy. Autophagy 5: 747-748, 2009.

28. Bauer PO, Wong HK, Oyama F, et al: Inhibition of Rho kinases enhances the degradation of mutant huntingtin. J Biol Chem 284 13153-13164, 2009.

29. Rodriguez-Perez AI, Dominguez-Meijide A, Lanciego JL, Guerra MJ and Labandeira-Garcia JL: Inhibition of Rho kinase mediates the neuroprotective effects of estrogen in the MPTP model of Parkinson's disease. Neurobiol Dis 58: 209-219, 2013.

30. Petratos S, Li QX, George AJ, et al: The beta-amyloid protein of Alzheimer's disease increases neuronal CRMP-2 phosphorylation by a Rho-GTP mechanism. Brain 131: 90-108, 2008.

31. Koyanagi M, Takahashi J, Arakawa Y, et al: Inhibition of the Rho/ROCK pathway reduces apoptosis during transplantation of embryonic stem cell-derived neural precursors. J Neurosci Res 86: 270-280, 2008.

32. Claassen DA, Desler MM and Rizzino A: ROCK inhibition enhances the recovery and growth of cryopreserved human embryonic stem cells and human induced pluripotent stem cells. Mol Reprod Dev 76: 722-732, 2009.

33. Mojumder DK, Sherry DM and Frishman LJ: Contribution of voltage-gated sodium channels to the $b$-wave of the mammalian flash electroretinogram. J Physiol 586: 2551-2580, 2008

34. Nakayama AY, Harms MB and Luo L: Small GTPases Rac and Rho in the maintenance of dendritic spines and branches in hippocampal pyramidal neurons. J Neurosci 20: 5329-5338, 2000.
35. Peng Y, Zhang J, Xu H,He J, Ying X and Wang Y: Neuroprotective effect of protease-activated receptor-2 in the hypoxia-induced apoptosis of rat RGC-5 cells. J Mol Neurosci 50: 98-108, 2013.

36. Wu X, Jin W, Liu X, et al: Cyclic AMP response element modulator-1 (CREM-1) involves in neuronal apoptosis after traumatic brain injury. J Mol Neurosci 47: 357-367, 2012.

37. Katai N, Kikuchi T, Shibuki H, et al: Caspaselike proteases activated in apoptotic photoreceptors of Royal College of Surgeons rats. Invest Ophthalmol Vis Sci 40: 1802-1807, 1999.

38. Hafezi F, Steinbach JP, Marti A, et al: The absence of c-fos prevents light-induced apoptotic cell death of photoreceptors in retinal degeneration in vivo. Nat Med 3: 346-349, 1997.

39. Shimizu S, Eguchi Y, Kamiike W, Matsuda $\mathrm{H}$ and Tsujimoto $\mathrm{Y}$ : Bcl-2 expression prevents activation of the ICE protease cascade. Oncogene 12: 2251-2257, 1996.

40. Katai N, Yanagidaira T, Senda N, Murata T and Yoshimura N: Expression of c-Jun and Bcl-2 family proteins in apoptotic photoreceptors of RCS rats. Jpn J Ophthalmol 50: 121-127, 2006.

41. Chen J, Flannery JG, LaVail MM, Steinberg RH, Xu J and Simon MI: bcl-2 overexpression reduces apoptotic photoreceptor cell death in three different retinal degenerations. Proc Natl Acad Sci USA 93: 7042-7047, 1996. 